УДК: $378: 147$

Спартак Юрійович Гогонянц (кандидат військових наук, с.н.с.)

Олег Андрійович Заболотний (кандидат військових наук, доцент)

Алла Олексіївна Клочко (кандидат педагогічних наук, н.с.)

Свген Григорович Руденко

Національний університет оборони Украӥни імені Івана Черняховського, Київ, Украӥна

\title{
МОДЕЛІ ПРОЄКТУВАННЯ ЗНАНЬ ЕКСПЕРТНО-НАВЧАЛЬНОЇ СИСТЕМИ ПІДГОТОВКИ ВІЙСЬКОВИХ ФАХІВЦІВ
}

\begin{abstract}
Сучасною тенденцією в підготовці майбутніх військових фахівців є використання нового класу інформачійних технологій навчання, а саме, експертно-навчальних систем, основним призначенням яких є рімення поставлених завдань. Виділено основні компоненти експертно-навчальної системи (ЕНС): база знань; модуль навчання; модуль вилучення знань; модуль тестування; машина виведення; пояснення. ЕНС побудована на трьох групах базових принципах: кібернетичних - відображають досвід попередніх досліджень систем штучного інтелекту, ЕНС; педагогічних - визначають приниии, на яких будується педагогічне проектування $i$ застосування ЕНС; психологічних - визначають вихідні положення $i$ розуміння психіки слухача, на яких трунтуються прочеси проектування $i$ використання ЕНС в професійній підготовці майбутніх військових фахівиів. Представлена структура ЕНС, яка складається з інтерпретатора (забезпечує послідовність реалізації правил для вирішення конкретного завдання) бази даних і знань (складається з фактів і правил предметної області) підсистем пояснень (дозволяють слухачеві отримати відповідь на питання: “Чому система приймає таке рішення?») ; інтелектуального редактора бази знань (призначений для модифікації наявних правил і додавання нових) інтерфейсу. Проаналізовано існуючі моделі подання знань експертно-навчальної системи підготовки військових фахівців: модель, заснована на використанні фреймів; логічна модель; модель, заснована на використанні правил (продукиійна модель); модель семантичної мережі. Показано області ефективного застосування розглянутих моделей. Аналіз показав раціональність застосування семантико-фреймовой моделі подання знань в системі підготовки військових фахівців зі складними логічними зв'язками між їх поняттями і визначеннями. Продемонстровано приклад побудови ЕНС з вибором комбінаційної, а саме семантико-фреймовой моделі подання знань. Виділено особливості семантико-фреймовой моделі подання знань: поняття, категорії, об'єкти представлені у вигляді фреймів, зв'язок між фреймами у вигляді семантичної мережі. Програмна реалізація моделі може бути виконана з використанням системи управління базами даних MS SQL. Використання EHC такої моделі набуває особливого значення у процесі розв'язання складних та проблемних ситуацій у процесі підготовки військових фахівців.
\end{abstract}

Ключові слова: інформаційні технологї̈, експертно-навчальна система, фрейм, слоти, семантико-фреймова модель.

\section{Вступ}

Проаналізовано існуючі моделі представлення знань. Показано області ефективного застосування розглянутих моделей. Продемонстровано приклад побудови експертно-навчальної системи з вибором комбінаційної, а саме семантико-фреймової моделі представлення знань.

Постановка проблеми. Інтенсивний розвиток сучасних інформаційних технологій та соціальноекономічні перетворення в суспільстві на їх основі потребують удосконалення процесу професійної підготовки військових фахівців. Забезпечення якісного освітнього рівня підготовки майбутніх військових можна досягти завдяки використанню сучасних інформаційних систем навчання, які дозволять знаходити самостійні рішення в складних проблемних та суперечливих ситуаціях 3 різним ступенем невизначеності, що зустрічаються в професійній практиці. Особливого значення у процесі розв'язання складних та проблемних ситуацій набуває використання експертнонавчальних систем.

Аналіз останніх досліджень і публікацій. У роботах науковців [1-3] розглянуто впровадження сучасних інформаційних технологій у процесі підготовки майбутніх фахівців. Проблема удосконалення професійної підготовки майбутніх фахівців на основі використання інформаційних технологій підготовки знайшла відображення у роботах вчених [4-6]. Сучасною тенденцією в підготовці майбутніх військових фахівців $\epsilon$ використання нового класу інформаційних 
технологій навчання - експертно-навчальних систем, основним призначенням яких $\epsilon$ розв'язання поставлених завдань [7]. У дослідженнях [2; 7] розкрито принципи побудови експертно-навчальних систем підготовки фахівців. У наших попередніх дослідженнях [8] обгрунтовано архітектуру експертно-навчальних систем $з$ підготовки військових фахівців, однією 3 підсистем якої є база знань.

Метою статті $\epsilon$ проаналізувати моделі проєктування знань експертно-навчальної системи підготовки військових фахівців.

\section{Виклад основного матеріалу дослідження}

Експертно-навчальна система (ЕНС) будується на основі знань експертів предметних галузей та реалізується у формі комп'ютерної програми, яка контролюе i здійснює процес навчання. Призначення такої системи полягає в тому, що вона, 3 одного боку, допомагає слухачам самостійно навчатися, а 3 іншого - викладачам навчати і контролювати слухачів [9].

Виділяють наступні основні компоненти ЕНС:

1. база знань;

2. модуль навчання;

3. модуль вилучення знань;

4. модуль тестування;

5. машина виведення;

6. система пояснень.

ЕНС базується на трьох групах базових принципів: 1) кібернетичні принципи відображають досвід попередніх досліджень в області систем штучного інтелекту, експертних та експертно-навчальних систем; 2) педагогічні принципи - визначають принципи, на яких будується педагогічне проектування i застосування ЕНС в освітньому процесі; 3) психологічні принципи - визначають вихідні положення та розуміння психіки слухача, на яких повинні будуватися процеси проектування i використання ЕНС у професійній підготовці майбутніх військових фахівців [10].

У процесі розробки ЕНС важливо обрати ефективну модель представлення знань. На сьогодні існують такі моделі представлення знань: семантична; продукційна; фреймова; логікопредикатна, а також їх комбінації.

ЕНС складається 3:

інтерпретатора, який забезпечує послідовність реалізації правил для розв'язання конкретного завдання на основі правил й фактів, що зберігаються в базі знань та базі даних;

бази даних і знань, яка складається з фактів та правил предметної галузі. Окрім того, в ній зберігаються константи, довідкові матеріали та проміжні дані;

підсистеми пояснень, які дозволяють слухачу отримати відповідь на питання: «Чому система приймає таке рішення?»;

інтелектуального редактора бази знань, який призначений як для модифікації наявних правил, так і додавання в базу знань нових;

інтерфейсу користувача, комплексу програм, який отримує результати i реалізує діалог користувача 3 системою на етапі введення інформації.

Структура такої ЕНС представлена на рис. 1.

Однією 3 найбільш важливих проблем, характерних для ЕНС, $є$ проблема подачі знань. Для того, щоб маніпулювати знаннями за допомогою комп'ютера, необхідно здійснити їх моделювання. У таких випадках необхідно відрізняти знання, призначені для обробки комп'ютером, від знань, які використовуються людиною. При великому обсязі знань треба спрощувати послідовні окремі елементи управління знаннями.

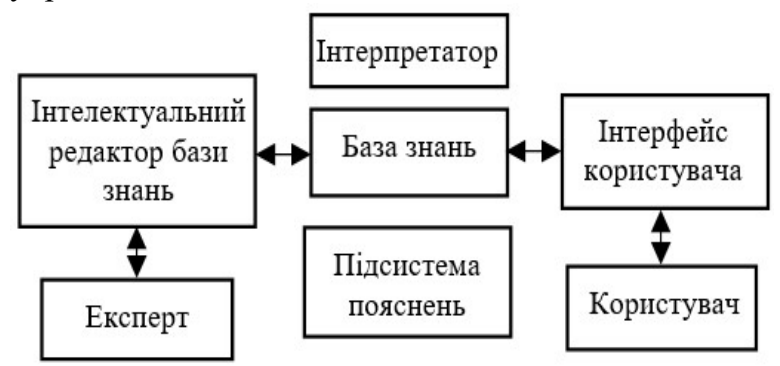

Рис. 1. Структура експертно-навчальної системи

При проектуванні моделей уявлення знань треба враховувати такі фактори, як простота розуміння та однорідність уявлень. Однорідні уявлення спрощують управління знаннями та логічними висновками. Подача знань має бути зрозуміла як користувачеві системи, так i експерту. В іншому випадку процес отримання знань та проведення їх оцінки ускладнюється.

Можна виділити наступні типові моделі подачі знань:

модель, заснована на використанні фреймів;

логічна модель;

модель, заснована на використанні правил (продукційна модель);

модель семантичної мережі [11].

Розглянемо кожну з представлених моделей.

Фреймова модель вперше запропонована М. Мінським [12], у якій фрейм означає абстрактний образ поняття, об'єкта, явища тощо. Інформація, яка відноситься до кадру, міститься в слоті (складова фрейму). Всі фрейми взаємопов'язані між собою та об'єднують процедурні знання, формуючи єдину фреймову систему.

Теорія фреймів слугувала поштовхом для розвитку кількох мов представлення знань, які стали досить поширеними мовами завдяки своїй гнучкості та широким можливостям.

Представлення знань на основі фреймової моделі, ефективне для структурного опису складних понять та вирішення завдань, в яких, відповідно до ситуації, бажано застосовувати різні способи виведення. У той же час на такій мові не можна управляти закінченням та сталістю 
цілісного образу. Зокрема, з цієї причини існує небезпека порушення приєднаної процедури та зациклення процесу виведення. Слід зазначити, що фреймова система без механізму приєднаних процедур найчастіше використовується як система продукції бази даних.

Логічна модель використовується для виведення закінчення за допомогою представлення знань в системі логіки предикаторів першого порядку.

Людська логіка - це інтелектуальна модель 3 нечітко визначеною структурою. У моделі, заснованій на використанні правил знання представлені сукупністю правил виду «ЯКЩО ТО». Продукційна система заснована саме на цій моделі. Ці системи $є$ двох типів - 3 прямим та зворотним зв'язком.

У продукційній системі 3 зворотним зв'язком будується дерево за допомогою правил I/АБО, що об'єднує в єдине ціле факти та висновки. Оцінка цього дерева на основі факту, що розміщений в базі даних, $є$ логічним висновком. Логічні висновки можуть бути прямими, зворотними та двонапрямленими [11].

Для прямих висновків точкою відліку є процес оцінки, коли представлені дані призупиняються на негативних вузлах, а гіпотези, що відповідають найвищому рівню дерева (корені), використовуються в якості висновків (якщо не все дерево було пройдено). Однак, для таких висновків характерним $є$ дерево, а також великі розміри даних, що не мають прямого відношення до висновків, які $\epsilon$ зайвими. Перевагою зворотного висновку є те, що оцінюється тільки та частина дерева, яка має відношення до висновку. У разі, якщо заперечення або затвердження неможливі, то породження дерева позбавлене сенсу. У двонапрямлених висновках спочатку запитуються дані, які необхідні для прийняття рішення щодо правильності даної гіпотези, а потім оцінюються невеликі обсяги отриманих даних й вибирається гіпотеза (за прикладом прямого висновку). На основі цих висновків реалізуються більш гнучкі та потужні системи.

Продукційна система включає наступні компоненти: інтерпретатор для отримання логічного висновку; база правил, що складається 3 набору правил виведення; база даних, що містить безліч фактів. Висновки виконуються у вигляді циклу «розуміння - виконання». Кожен цикл оновлює базу даних, яка буде виконувати частину обраних правил. У результаті вміст бази даних перетвориться від початкового до цільового, тобто цільова система синтезується в базі даних. Для виробничої системи характерний цикл вибору та виконання правил. За необхідності відбувається періодичне зіставлення за зразком у базі правил, адже із збільшенням кількості правил швидкість виведення істотно зменшується. Отже, такі системи не $є$ придатними для вирішення великомасштабних завдань.
У зв’язку з викладеним вище виділимо слабкі та сильні сторони продукційних систем. Сильними сторонами таких систем є простота: створення та розуміння окремих правил; поповнення та модифікації; механізму логічного висновку. До слабких сторін можна віднести: відмінність від структури людських знань; взаємне відношення незрозумілості правил; низька ефективність обробки; складність оцінювання; логіка введення уразі відсутності гнучкості.

Таким чином, якщо об'єктом $є$ невелика завдання, то проявляється тільки сильна сторона виробничої системи. У разі збільшення обсягу знань, необхідно робити гнучкі висновки або збільшувати швидкість виведення, що потребує структурованих знань та розв'язання складних завдань. У цьому випадку необхідно групувати знання та структурувати базу даних.

Модель семантичної мережі - це модель представлення знань на основі методів семантичної мережі, що має вигляд орієнтованого графа, вершини якого відповідають об'єкти предметної галузі, а дуги задають відносини між ними. Об'єктами можуть бути поняття, події, властивості, процеси.

Таким чином, семантична мережа є одним із способів представлення знань та відображає семантику предметної галузі у вигляді понять та відносин.

Для ЕНС підготовки військових фахівців ефективним $\epsilon$ представлення знань у вигляді семантико-фреймової моделі. У такі комбінованій моделі поняття, категорії, об'єкти представляються у вигляді фреймів, а зв'язок між фреймами здійснюється у вигляді семантичної мережі.

Розглянемо приклад побудови експертнонавчальної системи семантико-фреймової моделі представлення знань у системі підготовки військових фахівців.

На рис.2 представлено фрагмент семантикофреймової моделі представлення знань у системі підготовки військових фахівців.

Фрейм представляється у вигляді структури:

назва фрейма < (Слот 1, значення); (Слот 2, значення); (Слот 3, значення); ... (Слот N, значення) $>$.

Семантичний зв'язок встановлюється між фреймами у вигляді відношень.

У деяких випадках структура фрейма представляється у вигляді:

НАЗВА ФРЕЙМА:

(назва 1-го слота; значення 1-го слота),

(назва 2-го слота; значення 2-го слота),

$\ldots \ldots \ldots \ldots \ldots \ldots \ldots \ldots \ldots \ldots \ldots \ldots \ldots$

(назва N-го слота; значення N-го слота).

У теорії фреймів передбачається успадкування властивостей. У фреймах і в семантичних мережах спадкування відбувається за АКО - зв'язками (A-kind-of = це). Слот АКО вказує на фрейм більш вищого рівня. 


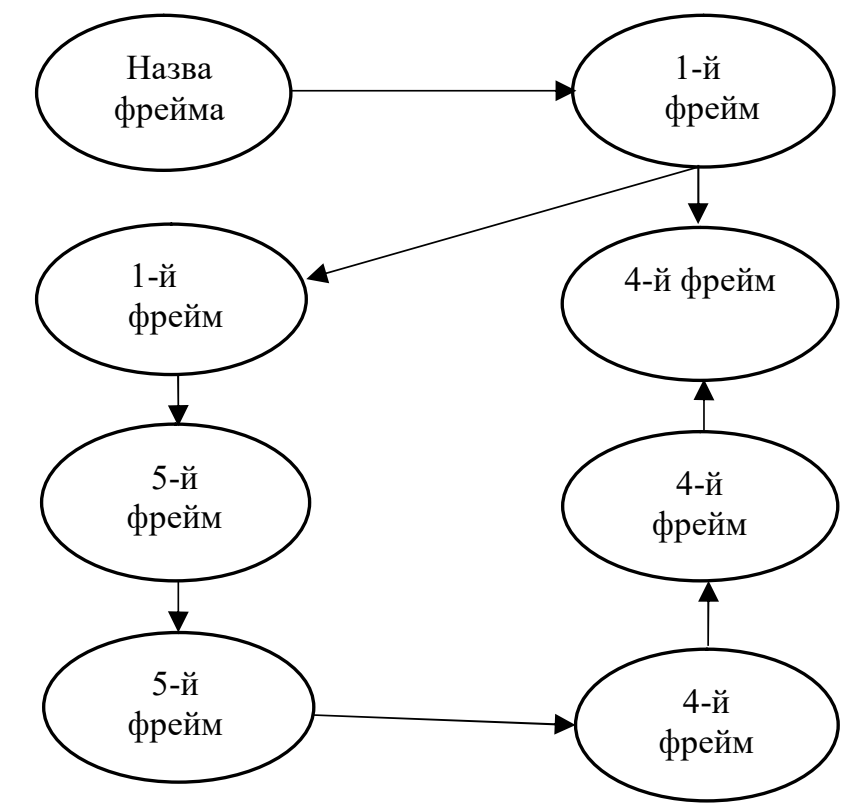

Рис. 2. Приклад семантико-фреймової моделі представлення знань

Програмна реалізація моделі може бути виконана 3 використанням системи управління базами даних MS SQL.

ЕНС мають дві категорії користувачів та два окремі входи, що відповідають різним цілям взаємодії користувачів 3 ЕНС. Доступ до підсистеми отримання знань має можливість тільки експерт. Вхід у підсистему захищений паролем. У даній підсистемі експерт може доповнювати базу знань новими правилами та модифікувати вже наявні правила в системі. ЕНС здатна відповідати на певні питання. Користувач може вводити параметри для визначення стійкості ланки, яка охоплена одиничним зворотним зв'язком.

\section{Jimepamypa}

1. Беляев М. И., Гриншкун В. В., Краснова Г. А. Технология создания электронных средств обучения. URL: http://uu.vlsu.ru/files/Tekhnologija_sozdanija_EHSO.pdf.

2. Голенков В. В., Гулякина Н. А., Елисеева О. Е. Инструментальные средства проектирования интеллектуальных обучающих систем: методическое пособие по курсу «Интеллектуальные обучающие и тренажерные системы» для студентов специальности «Искусственный интеллект». Минск: БГУИР, 1999. 102 c.

3. Джексон П. Введение в экспертные системы. Москва: Издательский дом «Вильямс», 2001. 624 с.

4. Бурдаев В. П. Клиент-серверная технология экспертной обучающей системы для сетей Интернет и Интранет. Искусственный интеллект. 2008. №3. С. 364 369.

5. Костюченко М. П. Інформаційно-кібернетичні та психолого-дидактичні аспекти проектування експертнонавчальних систем. Искусственный интеллект. 2013. № 4. C. $127-137$.

6. Словак К. Використання експертних систем під час узагальнення та систематизації у процесі навчання вищої математики. Наукові записки Тернопільського

\section{Висновки і перспективи подальших досліджень}

Таким чином, розглянуто існуючі моделі представлення знань та з'ясовано область їх ефективного застосування. Аналіз показав раціональність застосування семантико-фреймової моделі подання знань у системі підготовки військових фахівців зі складними логічними зв'язками між їх поняттями та визначеннями. У результаті розроблено приклад семантикофреймової моделі проєктування знань, яку можна використовувати використовувана у системі підготовки військових фахівців.

Подальші дослідження полягають у програмній реалізації ЕНС підготовки військових фахівців.

національного педагогічного університету імені Володимира Гнатюка. Серія: педагогіка. 2011. № 1. С. 141-148.

7. Петрушин В. А. Экспертно-обучающие системы. Киев: Наук. думка, 1992. 196 с.

8. Гогонянц С.Ю., Георгадзе О.А., Руденко Є.Г. Архітектура та класифікація експертно-навчальних систем 3 підготовки військових фахівців. Сучасні інформаційні технології у сфері безпеки та оборони. 2020. №2. C.133-138.

9. Гаврилова Т. А., Хорошевский В. Ф. Базы знаний интеллектуальных систем. Санкт-Петербург: Питер, $2000.384 \mathrm{c}$.

10. Шевчук О. Б. Педагогічні принципи проектування та розробки експертних систем навчання. Наукові записки Тернопільського національного педагогічного університету імені Володимира Гнатюка. Серія: педагогіка. 2016. № 1. С. 38-43.

11. Нейлор К. Как построить экспертную систему. Москва: Энергоатомиздат, 1991. 286 с

12. Minsky M. A. Framework for representing knowledge. In The Psychology of Computer Vision. McGraw-Hill: P. Winston, 1975. P. 211-277. 


\title{
МОДЕЛИ ПРОЕКТИРОВАНИЕ ЗНАНИЙ ЭКСПЕРТНО-ОБУЧАЮЩЕЙ СИСТЕМЫ ПОДГОТОВКИ ВОЕННЫХ СПЕЦИАЛИСТОВ
}

\author{
Спартак Юрьевич Гогонянц (кандидат военных наук, с.н.с.) \\ Олег Андреевич Заболотный (кандидат военных наук, доцент) \\ Алла Алексеевна Клочко (канддат педагогических наук, н.с.) \\ Евгений Григорьевич Руденко
}

Национальный университет обороны Украины имени Ивана Черняховского, Киев, Украина

Современной тенденцией в подготовке будущих военных специалистов является использование нового класса информационных технологий обучения, а именно, экспертно-обучающих систем, основным назначением которых является решение поставленных задач. Выделены основные компоненты экспертно-обучающей системы (ЭОС) база знаний; модуль обучения; модуль извлечения знаний; модуль тестирования; машина вывода; объяснения. ЭОС построена на трех группах базовых принципах: кибернетических - отражают опыт предыдущих исследований систем искусственного интеллекта, ЭОС; педагогических - определяют принципы, на которых строится педагогическое проектирование и применение ЭОС; психологических - определяют исходные положения и понимание психики слушателя, на которых основываются прочессы проектирования и использования ЭОС в профессиональной подготовке будущих военных специиалистов. Представлена структура ЭОС, которая состоит из интерпретатора (обеспечивает последовательность реализачии правил для решения конкретной задачи) базы данных и знаний (состочт из фактов и правил предметной области) подсистем объяснений (позволяют слушателю получить ответ на вопрос: "Почему система принимает такое решение?»); интеллектуального редактора базы знаний (предназначен для модификации имеюшихся правил и добавления новых) интерфейса. Проанализированы существуюшие модели представления знаний экспертно-обучающей системы подготовки военных специалистов: модель, основанная на использовании фреймов; логическая модель; модель, основанная на использовании правил (продукиионная модель); модель семантической сети. Показано области эффективного применения рассмотренных моделей. Анализ показал раџиональность применения семантико-фреймовой модели представления знаний в системе подготовки военных специалистов со сложными логическими связями между их понятиями и определениями. Продемонстрировано пример построения ЭОС с выбором комбинационной, а именно семантико-фреймовой модели представления знаний. Выделены особенности семантико-фреймовой модели представления знаний: понятие, категории, объекты представлень в виде фреймов, связь между фреймами в виде семантической сети. Программная реализация модели может быть выполнена с использованием системы управления базами данных MS SQL. Использование ЭОС такой модели приобретает особое значение в процессе решения сложных и проблемных ситуаций в процессе подготовки военных специалистов.

Ключевые слова: информаџионные технологии, экспертно-обучающая система, фрейм, слоты, семантико-фреймовая модель.

\section{MODELS OF KNOWLEDGE DESIGN OF EXPERT TRAINING SYSTEM FOR MILITARY SPECIALISTS}

\author{
Spartak Hohoniants (candidate of military sciences, senior researcher) \\ Oleg Zabolotny (candidate of military sciences, associate professor) \\ Alla Klochko (candidate of pedagogical sciences, research assistant) \\ Evgeny Rudenko
}

\section{National Defence University of Ukraine named after Ivan Cherniakhovskyi, Kyiv, Ukraine}

The current trend in the training of future military specialists is the use of a new class of information technology training, namely, expert training systems, the main purpose of which is to solve problems. The main components of the expert training system (ESS) are identified: knowledge base; training module; knowledge extraction module; testing module; output machine; explanation. ENS is based on three groups of basic principles: cybernetic - reflect the experience of previous studies of artificial intelligence systems, ENS; pedagogical - determine the principles on which the pedagogical design and application of ENS is based; psychological - determine the initial positions and understanding of the psyche of the listener, which are based on the processes of design and use of ENS in the training of future military professionals. The structure of ENS, which consists of an interpreter (provides a sequence of rules for solving a specific problem) database and 
knowledge (consists of facts and rules of the subject area) of explanation subsystems (allows the student to get an answer to the question: "Why does the system make such a decision?"); intelligent knowledge base editor (designed to modify existing rules and add new ones) interface. The existing models of knowledge representation of the expert-training system of military specialists training are analyzed: a model based on the use of frames; logical model; model based on the use of rules (production model); semantic network model. Areas of effective application of the considered models are shown. The analysis showed the rationality of the application of the semantic-frame model of knowledge representation in the system of training military specialists with complex logical connections between their concepts and definitions. An example of construction of ENS with the choice of combinational, namely semantic-frame model of knowledge representation is shown. Features of the semantic-frame model of knowledge representation are highlighted: concepts, categories, objects are presented in the form of frames, connection between frames in the form of a semantic network. The software implementation of the model can be performed using the MS SQL database management system. The use of such a model is especially important in the process of solving complex and problematic situations in the process of training military specialists.

Key words: information technologies, expert-educational system, frame, slots, semantic-frame model.

\section{References}

1. Belyaev M. I., Grinshkun V. V., Krasnova G. A. Technology of creating electronic learning tools. URL: http://uu.vlsu.ru/files/Tekhnologija_sozdanija_EHSO.pdf.

2. Golenkov V. V., Gulyakina N. A, Eliseeva O. E Tools for designing intelligent learning systems: a manual for the course "Intelligent learning and training systems" for students majoring in "Artificial Intelligence". Minsk: BGUIR, 1999. $102 \mathrm{p}$.

3. Jackson P. Introduction to expert systems. Moscow: Williams Publishing House, 2001. 624 p.

4. Burdaev V. P. Client-server technology of expert training system for Internet and Intranet networks. Artificial intelligence. 2008. №3. Pp. 364-369.

5. Kostyuchenko M. P. Information-cybernetic and psychological-didactic aspects of designing experteducational systems. Artificial intelligence. 2013. № 4. S. 127-137.

6. Slovak K. The use of expert systems in the generalization and systematization in the process of teaching higher mathematics. Scientific notes of Ternopil National Pedagogical University named after Volodymyr Hnatyuk. Series: pedagogy. 2011. № 1. S. 141-148.
7. Petrushin V. A. Expert-training systems. Kiev: Science. opinion, 1992. $196 \mathrm{p}$.

8. Hogonyants S. Yu., Georgadze O. A., Rudenko E. G. Architecture and classification of expert training systems for the training of military specialists. Modern information technologies in the field of security and defense. 2020. №2. P.133-138.

9. Gavrilova T. A., Khoroshevsky V. F. Knowledge bases of intelligent systems. Санкт-Петербург: Питер, 2000. 384 c.

10. Shevchuk O. B. Pedagogical principles of design and development of expert teaching systems. Scientific notes of Ternopil National Pedagogical University named after Volodymyr Hnatyuk. Series: pedagogy. 2016. № 1. S. 3843.

11. Naylor K. How to build an expert system. Moscow: Energoatomizdat, 1991.286 p

12. Minsky M. A. Framework for representing knowledge. In The Psychology of Computer Vision. McGraw-Hill: P. Winston, 1975. P. 211-277 